\title{
Can I wear festive attire on the wards?
}

With Christmas approaching, Abi Rimmer asks doctors whether festive trimmings are a "ho, ho, ho" or a "no, no, no" on the wards

\section{Abi Rimmer}

The BMJ

\section{Wear something festive but removable}

Sam Thenabadu (@4hrEmergencyDoc), consultant in adult and paediatric emergency medicine, says, "Working in the emergency department over the Christmas period is strange; despite the incessantly busy surroundings there is also a sense of festive fun. Being away from friends and family is, however, particularly noticeable and unwelcome. Those staff who have to work on Christmas Day might be offered a Christmas meal and token present, but it's rare that either staff or patients really want to be there.

"Christmas jumpers and Santa hats are an embedded part of the modern day Christmas period and so by default enter into the hospital setting. For the majority of staff, donning a Christmas pudding or jingling elf jumper has now become accepted uniform. It brings festivity to work and in some small way tempers the feelings of missing out. Patients also seem to respond well to them and a stressful patient journey can often be more relaxed because of these touches.

"A straw poll of my emergency department colleagues confirmed my suspicions that both tasteful and gregarious jumpers were actively being sourced for this year's Christmas period. When asked if there were any restrictions, all doctors and nurses commented, without prompting, that if a patient was very sick and more serious conversations were needed, slipping the jumper off and getting back into work wear would be the best option.

"With a range of Christmas jumpers in my cupboard, I will certainly don one for my Christmas Eve shift. God forbid any bad news needs breaking this Christmas but I'm sure that emergency department teams around the country will continue to be sensitive, caring, and compassionate to patients, relatives, and colleagues alike if it does-jumper or no jumper.

"Merry Christmas all."

\section{Being a patient gave me a new perspective}

Katherine Conroy (@kc_312), specialty trainee in ear, nose, and throat surgery, says, "Upon signing your NHS contract, Christmas Day at home becomes a privilege, not a right. So when the rest of the world is putting their out-of-office on and hunkering down with a stockpile of mince pies, healthcare professions rely on their colleagues' camaraderie for their festive cheer.

"This is why I embraced Christmas time as a hospital doctor; Wham on the ward radio, tinsel dangling from the ceiling tiles, piles of chocolates everywhere, and smiles all round. I wore brussels sprout socks and snowflake earrings, and sometimes even a seasonal jumper.

"But last year I spent Christmas in hospital in a different capacity: as a patient. A 'quick' trip to the emergency department became an emergency admission for a life threatening diagnosis. By 25 December I had been an inpatient for four weeks and, take it from me, nothing will unleash your inner Scrooge like being woken up on Christmas morning by the bleep of the observation machine.

"I couldn't find a scrap of joy on Christmas Day as a patient, with the possibility of it literally being my Last Christmas overshadowing proceedings. It dragged far more than your typical day, probably because there were fewer staff on and everything moved slowly. My care was excellent and everyone on the ward was lovely, but I just wanted to hibernate under my covers and wallow until Boxing Day.

"I feel ungrateful for not appreciating my medical team's efforts. They were missing out on Christmas too, and trying to make it easier for their patients. But save the Santa hats and elf ears for the staffroom this Christmas, for the sake of miserable humbugs like me."

\section{We can balance frivolity with the gravity of medicine}

Alessandra Glover Williams (@ alessglover), specialty trainee in neonatology and trainee representative for Severn at the Royal College of Paediatrics and Child Health trainees committee, says, "As a paediatric registrar approaching my fourth Christmas in a row at work, I am something of an expert when contemplating this question. To a paediatric patient, a Christmas jumper or tinsel garland might make their admission that little bit more enjoyable and their doctor a little bit more relatable. But is it professional?

"The GMC says that we should be considerate of patients, so let's examine the scope of our festive trimmings. I would hope that they would bring festivity, merriment, and cheerfulness, but there might be times when this isn't the case. I would also hope that the traditional western Christmas is far enough 
removed from Christianity that religious conflict is avoided, but again this should be considered.

"To a patient who is confused, delirious, or suffering from dementia, a Christmas theme could orientate them to the time of year, but over-commitment to your outfit could potentially lead to confusion.

"There is also a question around whether a festive jumper is compatible with resuscitation or breaking bad news. Having spent last Christmas in the emergency department with a young girl in status epilepticus, there were times when I questioned my elf jumper and reindeer socks. Fortunately, I knew that it wasn't the first time her family had seen her this unwell and we chatted until the early hours about our respective Christmas plans.

"Underneath the festive jumper I always wear a scrub top for those situations that do not afford frivolity. The decision can be made upon stepping into a room and I feel that with planning and thought we can balance spreading joy and hilarity with the gravity that our job demands.

"And to those 410000 NHS employees working this year-merry Christmas!"

\section{Christmas isn't joyful for everyone}

Carmen Soto (@gourmetpenguin), specialty trainee in paediatric oncology and chair of the BMA Women in Academic Medicine Group, says, "Christmas is coming-you can tell because the shop windows are full of festive jumpers, glittery dresses, and an array of Santa hats. As a paediatrician, I get a bit more leeway with my workwear and I do my fair share of dressing up when required. But Christmas raises a whole lot of questions about what is appropriate to wear.

"When you tell people that you're working in the children's hospital over Christmas, you get one of two responses: 'How sad' or 'That must be fun.' The reality is that it's both—often at the same time. Christmas in hospital can be traumatic and painful, but it can also be filled with hope and magic, creating precious memories for the future. There are families holding their Christmas a bit early-just in case 25 December is too late. And there will be families celebrating a Christmas that they weren't sure would ever happen for them. Dressing in the Christmas spirit can be a part of that.

"There are practicalities to consider, of course; running down a corridor scattering tinsel as you go isn't the most professional look. And while having a child trying to grab your antlers might be great distraction, it doesn't make for the most successful cannulation either. And then there's simply being aware that Christmas won't be a fun filled, magical time for everyone. The saddest sight at Christmas isn't a doctor doing cardiopulmonary resuscitation in a festive jumper; it's a child hiding away from any sign that it's Christmas because they won't be a part of it.

"Me? I'll be wearing my special Christmas shoes, earrings, and a party frock. Antlers optional—and easily removable."

\section{It can create a positive atmosphere at a difficult time}

Shivali Fulchand (@ shivalifulchand), BMJ editorial registrar and national medical director's clinical fellow, says, "Christmas jumpers make doctors look fun (for a change). We are one of the few staff in the hospital without a set uniform, so we should try to be creative in those rare moments offered.

"As a fresh faced foundation doctor, I was allocated the Christmas night shift in the general surgery department. In preparation for the big first night, I specially purchased a new jumper which had a big dinosaur with a Santa hat shouting "Merry Christmas" on it. I avoided buying any jumpers with bells that would jingle as I walked (or ran) down corridors or excessive glitter that might drop into a healing wound. It was a very considered buying process.

"Having narrowly avoided several varieties of bodily fluid, I'm not sure if a brand new jumper was a good idea on a surgical night shift. However, I found that festive clothing is a surprisingly good conversation starter, as well as a people pleaser.

"Feelings of isolation and loneliness can peak at Christmas time. If our duty as clinicians is the wellbeing of our patients, we should do what we can to create a positive atmosphere around the festive season. Wearing a funny jumper was my small contribution towards that. Most of the patients I met that night welcomed me warmly and complimented my choice. It also made my job cannulating and taking blood a lot easier, as they were often distracted by my jumper or the conversation about it.

"I wish I could wear Christmas jumpers every day."

\section{Be festive-but not in the emergency department}

Robert Hirst (@ hirstposition), specialty trainee in acute care common stem, says, "It's all about context. Last December I was working in acute medicine on a very festive Christmas Eve twilight shift, wearing an even more festive David Attenborough themed Christmas jumper.

"I was covering ambulatory care and clerking a patient sent in by his GP with a week long history of headache and blurred vision. He had a two month history of weight loss, a new diagnosis of diabetes, and the sort of blood sugars you'd see after eating a whole box of Celebrations. His GP had sent him for a computed tomography (CT) scan of the abdomen the week before. I sent him for a CT of his head. It showed a space occupying lesion. The CT his GP had sent him for showed a large pancreatic mass. I had to break the news of both, having hastily ditched the Christmas jumper and put on a scrub top.

"Wearing Christmas attire on the wards is fine, because you're trying to introduce a degree of mirth (or perhaps myrrth?) into what is otherwise a depressing situation. People appreciate the effort to brighten up their day.

"But while it might be okay to bring your Christmas sparkle to the elderly care ward, in the emergency department you see people whose lives have been disrupted. People who, until very recently, were with their friends and families, living their normal lives. I don't think these people need to know it's Christmas. They want you to look after them and return them to their normal lives without too much incident. I wouldn't wear Christmas clothing in the emergency department. It's too variable, too volatile-and you'll get vomit and blood all down your nice Christmas jumper." 